DOI 10. 18307/2020. 0521

(c) 2020 by Journal of Lake Sciences

\title{
大型深水水库溶解氧层化结构演化机制”
}

\author{
余 晓 ${ }^{1 * *}$, 诸葛亦斯 ${ }^{1}$, 刘晓波 $^{1}$, 杜 强 ${ }^{1}$, 谭 宏 $^{2}$ \\ (1: 中国水利水电科学研究院, 北京 100038) \\ (2:广州市水务科学研究所,广州 510220 )
}

\begin{abstract}
摘 要: 深水水库溶解氧 (DO) 的演化成因目前尚不完全清楚, 研究其演变机制对制定水库水质保护和管理策略十分重 要. 本文以我国京津冀地区重要的大型深水水源水库潘家口水库为例, 系统分析了水库水温和 DO 浓度的时空分布特征、 演化成因, 以及水库的水质响应情况. 结果表明: 4 月中旬- 11 月底该水库存在显著的季节性热分层, 水库热分层为 DO 层化结构的形成提供了垂向分异性物理环境; 与热分层类似, DO 层化表现为 3 层结构, 本文从上至下将其分别定义为混 合层、氧跃层和氧亏层. 垂向各层不同生化过程的作用为 DO 浓度空间差异性演变提供了驱动力, 其中混合层受浮游藻类 过量生长的影响, DO 往往处于过饱和状态; 氧跃层受大量生物的呼吸及有机物分解等耗氧的影响, DO 浓度急剧下降,78 月一般处于缺氧状态 $(\mathrm{DO}<2 \mathrm{mg} / \mathrm{L})$; 氧亏层受重污染沉积物耗氧的影响, DO 浓度持续下降, 热分层末期水库底部可能 出现缺氧. 热分层末期 DO 浓度降低的同时, 沉积物中会发生 Mn 的还原、Mn-P 解吸释放等现象, 但沉积物中含量较高的 $\mathrm{Fe}$ 没有发生还原以及 $\mathrm{Fe}-\mathrm{P}$ 的解吸释放现象. 潘家口水库目前正在逼近缺氧、内源污染大量释放的临界点,其水环境治理 应予以高度重视.
\end{abstract}

关键词: 溶解氧层化结构;演化机制;深水水库;潘家口水库

\section{Evolution mechanism of dissolved oxygen stratification in a large deep reservoir *}

\author{
YU Xiao ${ }^{1 * *}$, ZHUGE Yisi $^{1}$, LIU Xiaobo $^{1}$, DU Qiang $^{1} \&$ TAN Hong $^{2}$ \\ (1: China Institute of Water Resources and Hydropower Research, Beijing 100038, P.R.China) \\ (2: Guangzhou Institute of Water Sciences, Guangzhou 510220, P.R. China)
}

\begin{abstract}
The cause of dissolved oxygen (DO) evolution in deep reservoirs still remains unclarified. However, it is important to explore the evolutionary mechanism for water quality protection and management. This paper systematically analyzed the spatiotemporal variations of water temperature and DO, as well as the water quality response to these factors, in the Panjiakou Reservoir, a large deep reservoir in Beijing-Tianjin-Hebei region. Results show that the reservoir has a significant seasonal thermal stratification during mid-April to the end of November, which creates a vertically specific environment for the DO stratification. Similar to the thermal stratification, the DO stratification also shows a three-layer structure from top to down, namely, the mixed layer, the oxycline and the oxygen-deficient layer. Different biochemical processes in each layer determinate the spatial variability DO evolution. Due to excessive planktonic algae, DO is supersaturated in the mixed layer. While in the oxycline layer, DO concentration declines sharply as a result of respiration and organic matter decomposition, becoming hypoxic (i.e., DO<2 mg/L) in July and August. Due to the oxygen consumption of severely contaminated sediments in the oxygen-deficient layer, DO concentration declines continuously, potentially leading to hypolimnion at the bottom of the reservoir at the end of thermal stratification. Meanwhile, in this area, Mn reduction reaction occurs and the Mn-P is released to the hypolimnion. However, there is no Fe reduction reaction or Fe-P released. In summary, the Panjiakou Reservoir is approaching a critical point of hypoxia and massive release of endogenous pollutants. Special attentions should be paid on its water environment treatment.
\end{abstract}

Keywords: Dissolved oxygen stratification; evolution mechanism; deep water reservoirs; Panjiakou Reservoir

\footnotetext{
* 2019-12-23 收稿; 2020-02-18 收修改稿. 国家重点研发计划项目 (2016YFC0401701) 资助.

** 通信作者; E-mail:yxseu@ 126.com.
} 
深水水库, 特别是一些调节能力强的大型水库, 其水库库容大、流速小, 每年夏季会出现明显的热分层 现象 ${ }^{[1-2]}$. 近年来, 流域污染负荷的大量增加导致水体浮游植物生物量增加、水华现象时有发生, 深水水库热 分层期间缺氧问题严重, 水体缺氧已成为严重的全球性生态环境问题 ${ }^{[3-6]}$. 水体缺氧会导致鱼类等水生生物 死亡、沉积物中大量还原物质释放等问题,释放的硫化氢等气体将导致水体发臭; 同时,大量磷、氨氮等内源 污染的释放会为藻类等浮游生物的生长提供营养盐, 加剧藻类生长, 对水生生态系统造成显著不利影 响 ${ }^{[5,7-8]}$. 溶解氧 (DO) 对良好水质和健康生态系统的重要性已经得到了湖库管理者广泛认可, 对 DO 最低浓 度的要求已被纳人相关标准 ${ }^{[9-11]}$.

深水水库热分层使得垂向各层水体的水动力特征差异明显,影响物质空间分布,并对水体 DO 的垂向分 布产生显著影响 ${ }^{[12]}$. 由于水库内部能质体系的多样性和复杂性, 当前对 DO 的演化过程和成因尚不清楚 ${ }^{[11]}$. 一般而言, 受地理气候、水动力条件、营养状态等影响, 湖库内 DO 呈现出多种垂向分布模式 ${ }^{[13-14]}$, 贫营养型 水库, 水体透明度较高, DO 浓度随时间变化小, 其在垂向的分布基本均匀, 部分湖库下层 DO 浓度略高于上 层; 富营养型水库, 由于表层初级生产力较高, 表层 DO 浓度较高、甚至出现超饱和,下层 DO 浓度随着深度 的加大逐渐降低, 底部可能出现缺氧甚至无氧现象 ${ }^{[14]}$. 因此, DO 浓度及其空间分布特征在一定程度上可刻 画热分层水体的营养状况, 研究 DO 的演变过程有助于客观评价水库的水环境状况, 对制定水库水环境保护 和管理策略至关重要 ${ }^{[15-16]}$.

潘家口水库是我国华北地区重要的大型深水水源水库, 1990s 以来受上游来水污染负荷增加以及库区 大面积网箱养殖的影响, 水库氮磷负荷增加, 营养状况急剧恶化 ${ }^{[17-18]}$. 在氮磷等生源要素长期高浓度作用 下, 潘家口水库水环境状况及演变趋势是目前水库管理中被高度关注的问题. 本文以潘家口水库为案例, 系 统调查了水库水温和 DO 浓度的时空分布特征, 分析了在热分层与污染负荷双重作用下水库 DO 层化结构 的演化成因及水质响应, 以期深化对大型深水水库水环境演变特征的认识, 为该类水库的水环境保护提供 科学指导.

\section{1 材料与方法}

\section{1 研究区域概况}

潘家口水库建于 1980 年, 位于河北省承德、唐山交界处的滦河干流, 承德市下游, 控制流域面积 3.37 万 $\mathrm{km}^{2}$, 主要为高原和山地, 主要土壤类型为棕壤, 其地理位置如图 1 所示 ${ }^{[19-20]}$. 流域内多年平均气温为 $2 \sim$ $11^{\circ} \mathrm{C}$, 多年平均降水量为 $300 \sim 800 \mathrm{~mm}$. 潘家口水库作为引滦人津工程的龙头水库, 承担着向天津市、唐山市 供水的任务, 兼顾防洪、发电 ${ }^{[17]}$. 该水库为峡谷型深水水库, 回水长度 $80 \mathrm{~km}$, 水域面积 $69 \mathrm{~km}^{2}$, 库区水面宽 $200 \sim 1000 \mathrm{~m}$, 平均水面宽不足 $500 \mathrm{~m}$; 水库近 10 年最大水深的变幅为 $33 \sim 69.11 \mathrm{~m}$, 均值为 $54.74 \mathrm{~m}$; 现状总 库容 19.13 亿 $\mathrm{m}^{3}$, 近 10 年平均来水量 8.71 亿 $\mathrm{m}^{3}$, 平均水力停留时间 2.20 年, 该水库为多年调节水库 ${ }^{[17]}$.

1990s 以来, 潘家口水库总氮 $(\mathrm{TN})$ 、总磷 $(\mathrm{TP})$ 浓度持续升高, 长期处于 $\mathrm{V}$ 类 劣 $\mathrm{V}$ 类水平, 水体处于富 营养化状态 ${ }^{[18]}$. 这一方面与水库来水水质常年为劣 $\mathrm{V}$ 类, 主要超标指标为 $\mathrm{TP} 、$ 氨氮、 $\mathrm{TN}$ 有关 ${ }^{[17,21]}$; 另一方 面也与历史上该水库网箱养鱼无序发展、饵料大量施用加重库底沉积物污染有关 ${ }^{[22]}$.

\section{2 采样仪器及参数测定}

2017 年 5 月- 2018 年 11 月对潘家口水库沿程 16 个监测点水温和 DO 浓度进行了逐月垂向监测, 具体 如图 2 所示. 采用 YSI EXO 便携式水质监测仪进行垂向现场监测, 主要指标包括水深、水温、DO 浓度、叶绿 素 $a$ 浓度等,垂向每 $0.2 \mathrm{~m}$ 记录一次数据.

同时,2018 年 5 月、8 月、11 月对坝前 (监测点 16) 进行分层水质监测, 主要监测指标有 TP、铁 ( Fe)、锰 ( Mn) 等. 分层水质监测, 采用卡盖式分层采水器, 表水层和温跃层每 $5 \mathrm{~m}$ 采集一个水样,滞温层每 $10 \mathrm{~m}$ 采集 一个水样, 并在库底以上 $1 、 3 、 5 \mathrm{~m}$ 分别采集水样. 水样冷藏于保温箱中带回实验室, 各项指标均采用国家标 准方法 (GB 11911－1989) 测定,其中 TP 浓度采用钼酸铵分光光度法测定, Fe、Mn 浓度采用火焰原子吸收分 光光度法测定. 


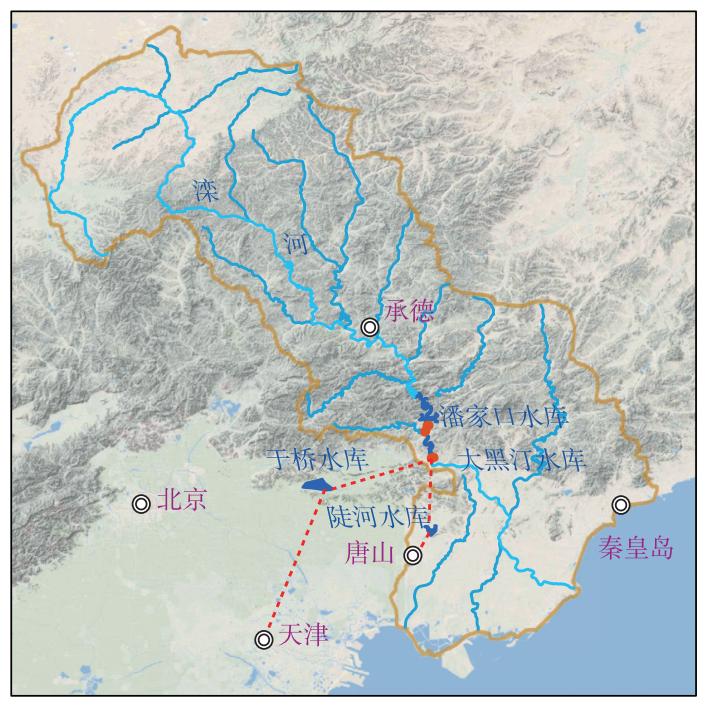

图 1 滦河流域及潘家口水库位置

Fig.1 Location of Luanhe River Basin and the Panjiakou Reservoir

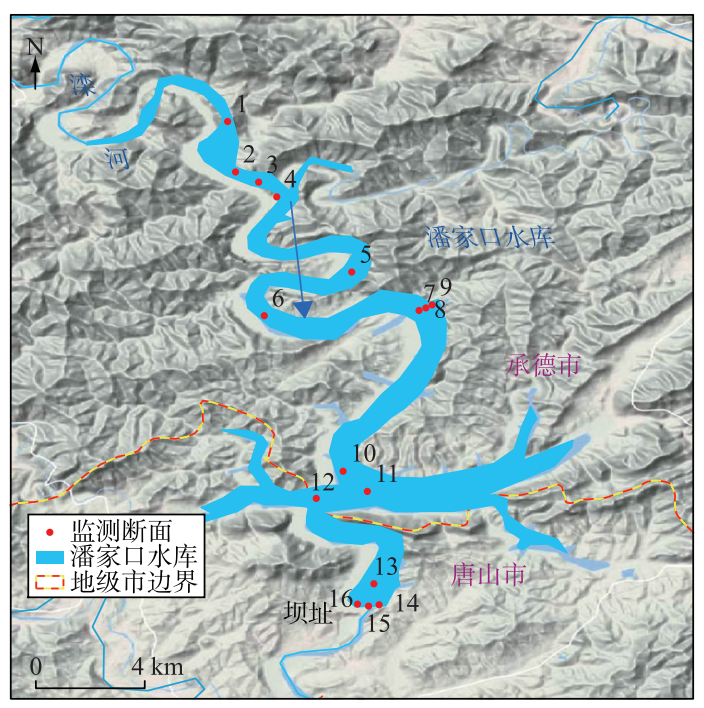

图 2 潘家口水库监测点位分布

Fig.2 Distribution of monitoring sites in Panjiakou Reservoir

\section{2 结果}

\section{1 水温的时空分布特征}

从 2017-2018 年水温的垂向分布看, 潘家口水库水温的垂向分布存在明显的季节性特征, 表现为以年 为尺度的热分层一混合模式循环 (图 3, 图 4). 4 月下旬一 11 月末水库呈现热分层状态, 水温上高下低, 呈单 温跃结构, 水体在垂向可分为表水层、温跃层和滞温层, 热分层持续时间约为 210 天; 12 月一次年 4 月水库处 于垂向均匀混合状态.

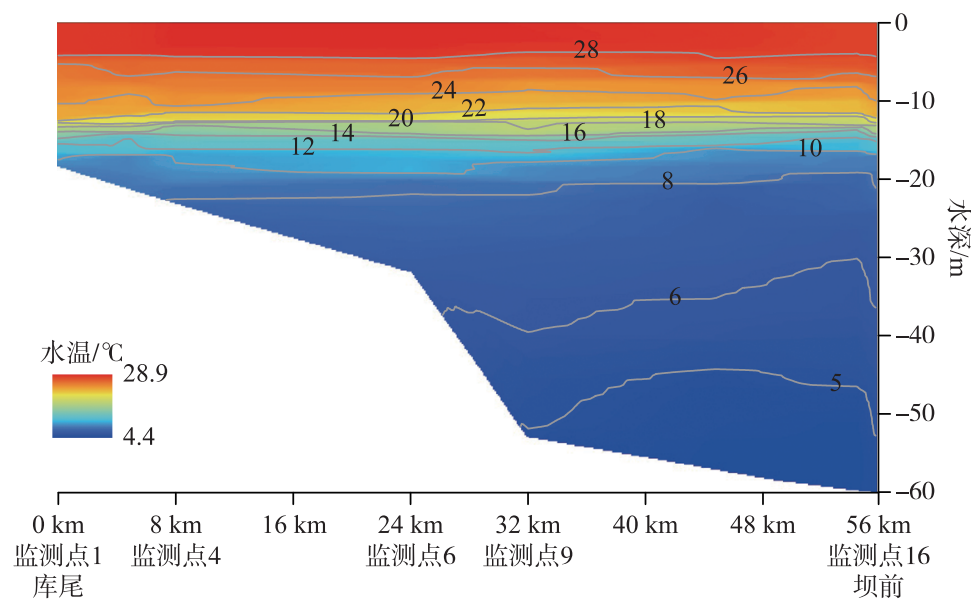

图 3 潘家口水库 2017 年 8 月纵向水温分布

Fig.3 Longitudinal distribution of water temperature of the Panjiakou Reservoir in August of 2017

图 3 为 2017 年 8 月水温监测的结果, 由该图可知, 潘家口水库最大坝前水深为 $60 \mathrm{~m}$, 从库尾至坝前 56 $\mathrm{km}$ 的库区河道内水温的垂向分布特征具有共性, 水库各断面均处于稳定的热分层状态. 表水层水温均为 
$28.9^{\circ} \mathrm{C}$, 从水深 $5 \mathrm{~m}$ 开始水温随水深增加而急剧下降, 水深超过 $20 \mathrm{~m}$ 后水温基本不变, 保持在 $4.4^{\circ} \mathrm{C}$ 左右.

以位于水库坝前的监测点 16 为例分析水温随时间的变化 (图 4, 图 5). 潘家口水库表水层水温年际变 化与气温基本一致, 但有一个月左右的滞后期, 全年水温变化范围为 $2.4 \sim 30.2^{\circ} \mathrm{C}$; 滞温层的水温变化范围为 $2.4 \sim 7.7^{\circ} \mathrm{C}$. 混合期水温垂向均匀分布, 4 月初水库垂向水温均为 $4^{\circ} \mathrm{C}$, 随着气温的升高表水层水温逐渐升高, 垂向热分层结构逐渐形成. 8 月表水层水温达到最大值 $30.2^{\circ} \mathrm{C}$, 滞温层水温略有升高, 达到 $4.7^{\circ} \mathrm{C}$, 此时表、底 温差最大. 之后随着气温的下降表水层水温逐渐降低, 表水层厚度增加, 至 11 月底表水层水温降为 $10.3^{\circ} \mathrm{C}$, 在此过程中滞温层的水温缓慢升高至 $7.7^{\circ} \mathrm{C} .11$ 月底水库表、底温差变小, 热分层稳定性减弱, 在强风等外力 扰动下发生垂向混合, 至 12 月底垂向水温均匀混合, 混合后水温为 $5.5^{\circ} \mathrm{C}$. 之后水库水温继续降低, 至 1 月 底水温达到最低值 $2.4^{\circ} \mathrm{C}$, 冬季水库不封冰. 1 月之后随着气温的升高, 水库水温同步升高, 至 4 月初水库水 温升高至 $4^{\circ} \mathrm{C}$, 水库仍表现为均温状态.

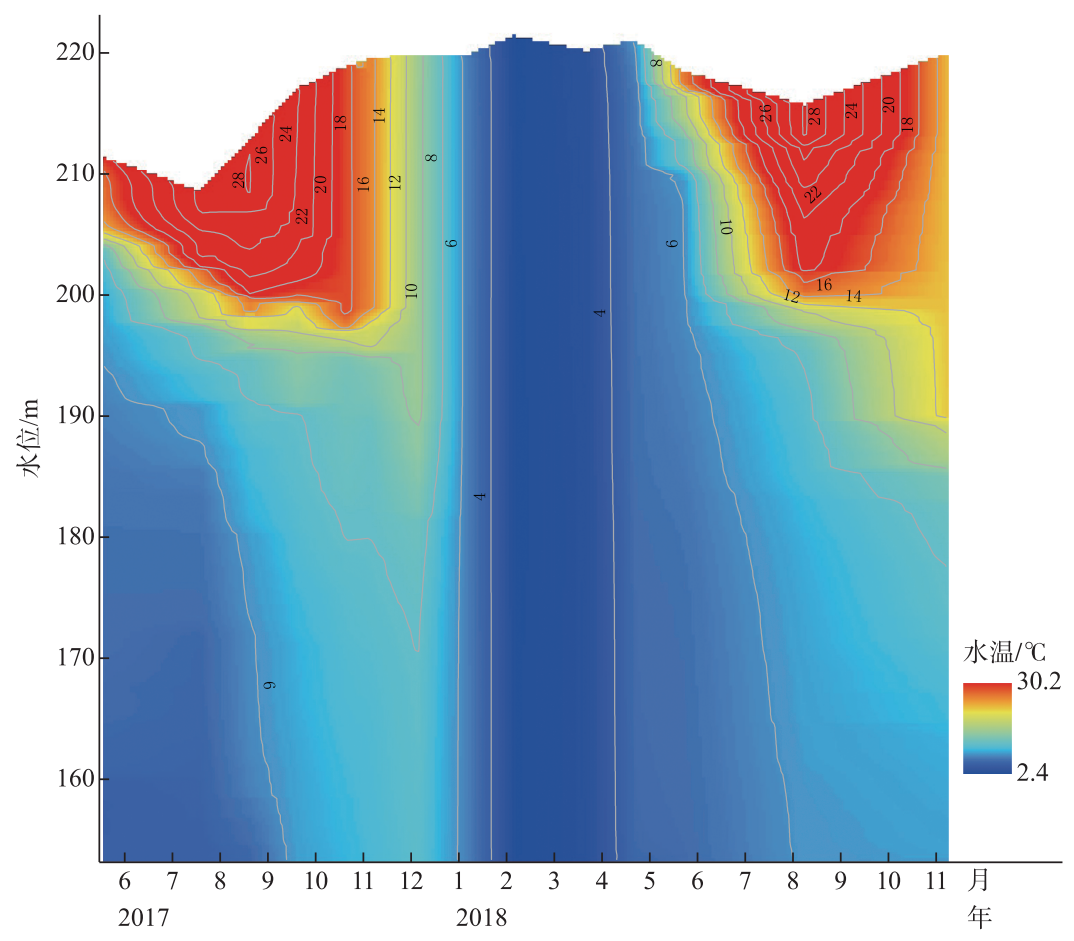

图 4 潘家口水库坝前 (监测点 16) 垂向水温年内变化

Fig.4 Annual change of vertical water temperature of the Panjiakou Reservoir (monitoring point 16)

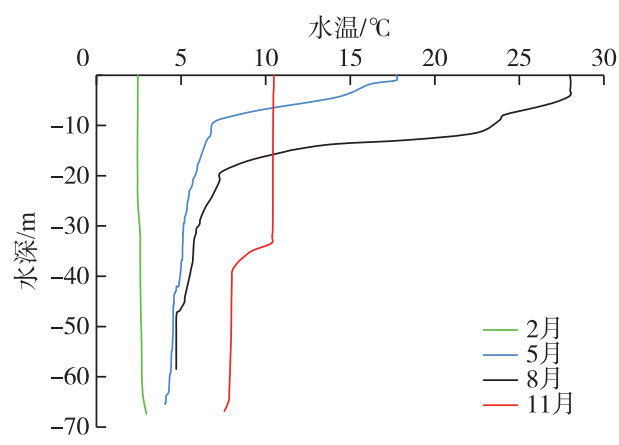

图 5 潘家口水库坝前 (监测点 16 ) 典型时段水温垂向剖面

Fig.5 Depth profiles of water temperature in typical periods of the Panjiakou Reservoir (monitoring point 16) 


\section{2 溶解氧浓度的时空分布特征}

与水温分层相似,潘家口水库 $\mathrm{DO}$ 浓度变化也具有显著的季节性分层特征. 以坝前监测点 16 为例 (图 6, 图 7), 1-5 月水库 DO 沿垂向均匀分布, 4 月中旬水温分层逐渐形成, 此时 DO 浓度在垂向基本不变, 均在 $11 \mathrm{mg} / \mathrm{L}$ 以上; 随着水温分层的发展, DO 在垂向也逐渐出现分层, 呈现出与水温分层类似的 3 层结构, 本文 将其从上至下分别称为混合层、氧跃层和氧亏层; 11 月底随着水温分层的破坏, DO 垂向分层也逐渐消失, 至 12 月底 DO 垂向浓度分布均匀. 混合层 DO 全年均匀分布, 浓度维持在 $9 \mathrm{mg} / \mathrm{L}$ 以上, 基本处于过饱和状态, 最大浓度可达 $15 \mathrm{mg} / \mathrm{L}$. 氧跃层 DO 浓度随水深的增加急剧降低, 在热分层最稳定的 7-8 月 DO 浓度低于 2 $\mathrm{mg} / \mathrm{L}$, 部分时段甚至低于 $1 \mathrm{mg} / \mathrm{L}$, 达到整个垂向上的最小值. 氧亏层位于水库的下层, DO 浓度随着分层的 发展持续下降, 在 DO 分层初期为 $10.5 \mathrm{mg} / \mathrm{L}, 2017$ 年和 2018 年 DO 分层末期浓度分别减小至 1.3 和 1.97 $\mathrm{mg} / \mathrm{L}$, 平均耗氧率约为 $0.045 \mathrm{mg} /(\mathrm{L} \cdot \mathrm{d})$.

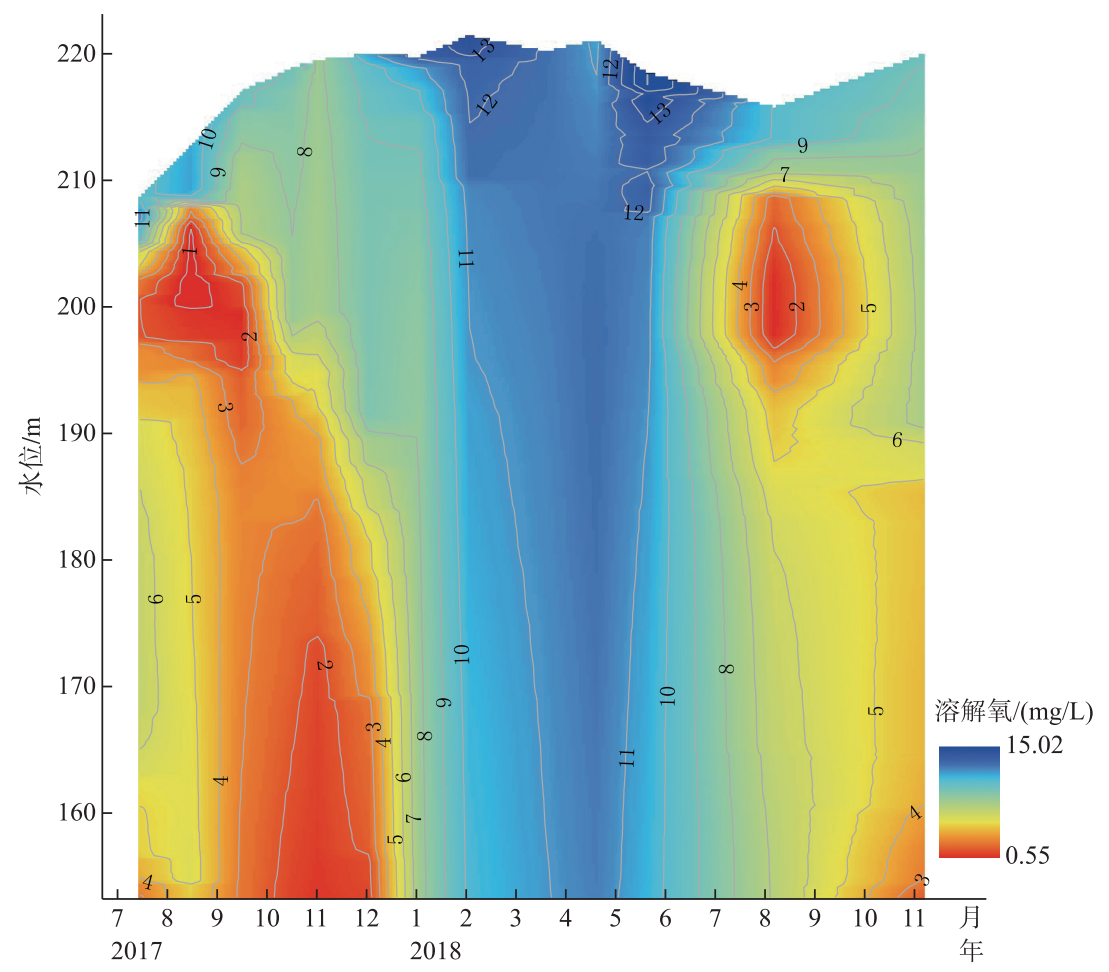

图 6 潘家口水库(监测点 16)垂向溶解氧浓度的年际变化

Fig.6 Annual change of vertical dissolved oxygen concentration distribution of the Panjiakou Reservoir (monitoring point 16)

从 2017 年 8 月潘家口水库热分层期间 DO 浓度沿水库纵向的分布 (图 8) 来看, 沿程各监测点 DO 浓度 的垂向分布特征较为一致, 整个水库 DO 均呈分层状态, 混合层厚度沿程总体相同, 在坝前和库尾略有增加, 库中断面混合层厚度最小. 氧跃层内 DO 浓度随水深的增加从 $10 \mathrm{mg} / \mathrm{L}$ 急剧减小, 最低均降至 $1 \mathrm{mg} / \mathrm{L}$ 以下, 形成的 DO 低浓度带从库尾延伸至坝前. 氧亏层 DO 浓度在库中至坝前段沿水深先升后降, 坝前库底 DO 浓 度约为 $3.5 \mathrm{mg} / \mathrm{L}$; 水深小于 $25 \mathrm{~m}$ 的库尾段 (纵向 $0 \sim 20 \mathrm{~km}$ ) 氧亏层内 $\mathrm{DO}$ 浓度均在 $2 \mathrm{mg} / \mathrm{L}$ 以下, 部分区域 DO 浓度甚至低于 $1 \mathrm{mg} / \mathrm{L}$. 


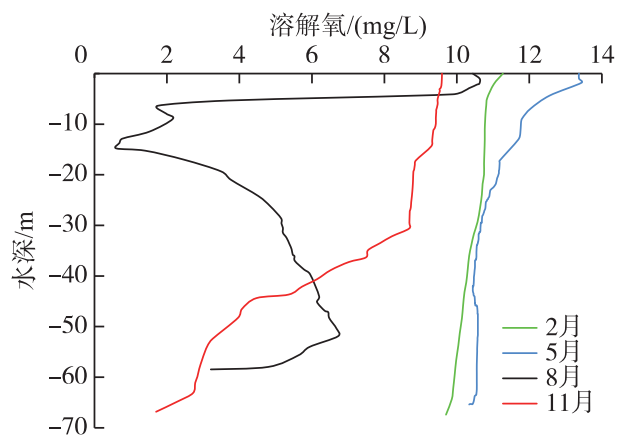

图 7 潘家口水库坝前 (监测点 16) 典型时段溶解氧的垂向剖面

Fig.7 Depth profiles of dissolved oxygen in typical periods of the Panjiakou Reservoir (monitoring point 16)

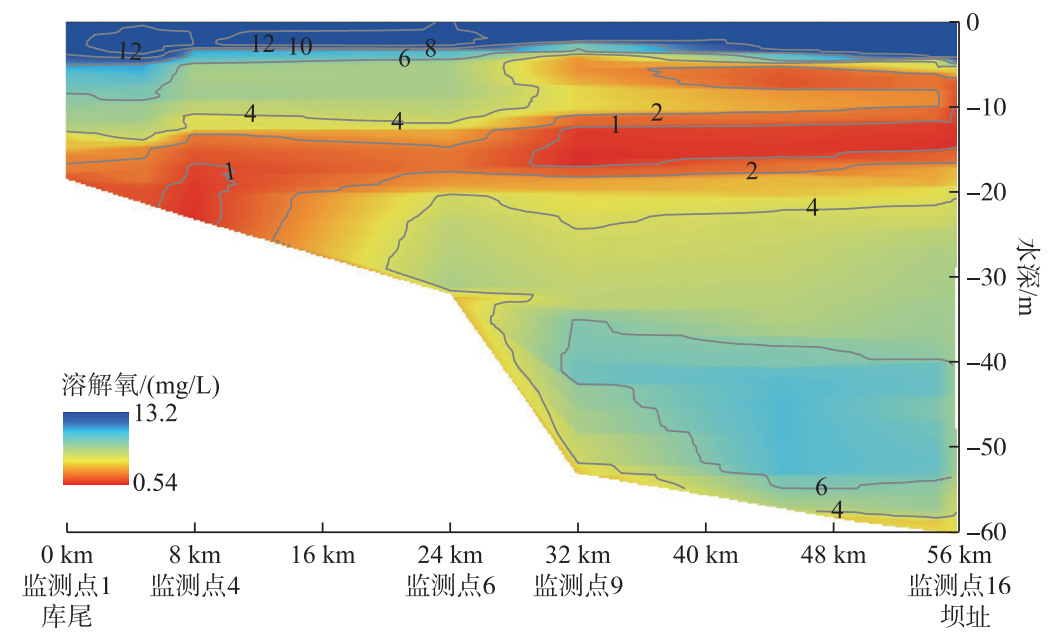

图 8 潘家口水库 2017 年 8 月纵向溶解氧浓度分布

Fig.8 Longitudinal dissolved oxygen concentration distribution of the Panjiakou Reservoir in August of 2017

\section{3 讨论}

\section{1 水库水温分层特征及演化过程分析}

本文通过计算分层情况下水温、DO 各层的厚度及界面垂向位置来定量分析水库水温和 DO 浓度的垂向 变化特征. 其中,采用 $0.2^{\circ} \mathrm{C} / \mathrm{m}$ 的温度梯度作为热分层期温跃层与上、下各层间界面的判别标准,计算坝前 监测点表水层、温跃层和滞温层的厚度 ${ }^{[3,23-24]}$; 采用 $0.2 \mathrm{mg} /(\mathrm{L} \cdot \mathrm{m})$ 的浓度梯度作为氧跃层与上、下各层间界 面的判别标准, 计算坝前监测点 DO 分层期间混合层、氧跃层和氧亏层的厚度 ${ }^{[3,24]}$; 采用表水层厚度 $\left(Z_{\mathrm{e}}\right)$ 与 水库最大深度 $\left(Z_{\text {max }}\right)$ 的比值为水库热分层稳定性系数 $\left(Z_{\mathrm{e}} / Z_{\text {max }}\right)$, 其数值越大则热分层稳定性越弱, 比值小 于 0.5 表征水库处于稳定分层状态 ${ }^{[2,25]}$.

由计算结果 (图 9) 可以看出,4 月中旬-11 月底是水库的热分层期,其间各层厚度随时间变化的特征各 不相同,该时段内表水层厚度随时间持续增加,热分层末期达到 $20.4 \mathrm{~m}$; 温跃层厚度呈现先增后减的趋势, 8 月达到最大值 $17.9 \mathrm{~m}$; 滞温层的厚度变化与表水层相反,随着热分层的逐渐持续减小,2017 年从热分层初期 的 $49.3 \mathrm{~m}$ 减至热分层末期的 $36.7 \mathrm{~m}$.

水库热分层稳定性随时间呈现由强变弱的特征,2017 年 5-8 月份热分层稳定性系数 $Z_{\mathrm{e}} / Z_{\text {max }}$ 不足 0.1 , 分层极为稳定; 随着热分层的持续, 该系数在 10 月初、 11 月初分别增至 $0.2 、 0.31$, 直至热分层末期( 11 月底) 


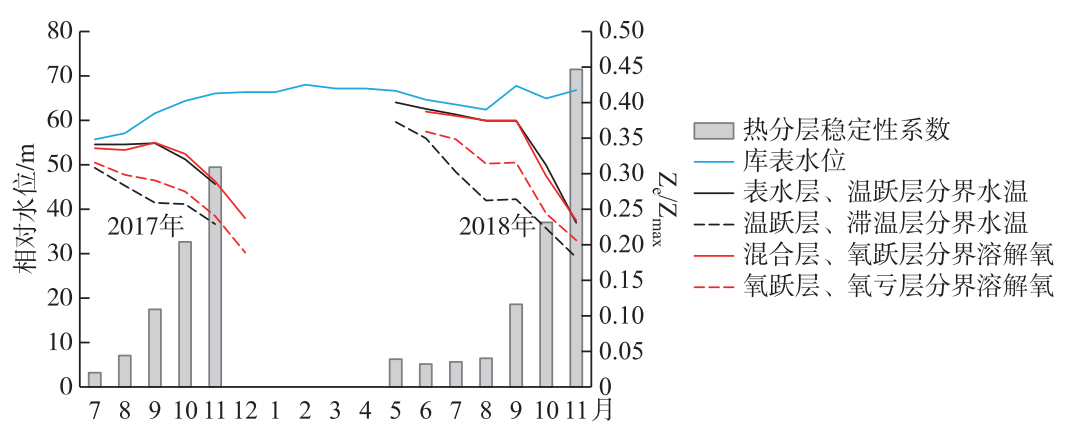

图 9 热分层期间潘家口水库水温、溶解氧分层结构和热分层稳定性系数

Fig.9 Stratification structure of water temperature, dissolved oxygen and thermal stratification stability of the Panjiakou Reservoir during thermal stratification

的 0.5. 热分层的稳定程度与水库水体交换的关系显著 ${ }^{[26]}$, 潘家口水库为多年调节水库, 2017 年人库径流量 仅为 8.86 亿 $\mathrm{m}^{3}$, 水库蓄水量为 16.82 亿 $\mathrm{m}^{3}$, 水库水力停留时间为 1.9 年, 上游来水对水库内水体的扰动较 小,水库热分层稳定性强.

水库热分层使得垂向各层水体内水动力条件差异显著. 水库中温跃层作为表层暖水向底层冷水过渡的 中间层, 较大的温度梯度导致较大的密度梯度, 可抑制水体的垂向混合 ${ }^{[14]}$. 同时,水库的表、底温差是决定 水库在秋冬季节垂向翻转、形成上下等温状态这一时间出现时机的主要因素, 温差越大翻转出现的时间越 晚 ${ }^{[14]}$. 潘家口水库热分层期间温跃层的厚度在 $4.4 \sim 17.9 \mathrm{~m}$ 间波动, 表、底温差较大, 温度梯度为 $0.28 \sim$ $3.22^{\circ} \mathrm{C} / \mathrm{m}, 7 、 8$ 月温跃层厚度和温度梯度均最大, 温差最大达到 $20.97^{\circ} \mathrm{C}$. 水库较大的表、底温差限制了水体 垂向掺混,该水库秋、冬季节垂向混合的时间比周边水库晚 1 个月左右 ${ }^{[14,27]}$.

水库的表水层在风力扰动和太阳辐射作用下垂向混合均匀,厚度往往逐渐增加 ${ }^{[28]}$. 对潘家口水库而 言, 5-8 月主要受太阳辐射增强的影响, 9-11 月随着气温下降表层冷水下沉加剧垂向对流混合, 使得表水 层厚度持续增加.

滞温层作为温度最低的下层, 其水温变化主要是水体对流和紊动造成的. 温跃层较大的温度梯度有效 抑制了物质和能量在垂向的传递, 特别是有效阻止了水面风浪等对滞温层的扰动, 使得滞温层水体紊动微 弱,一般不会发生强烈的混合作用 ${ }^{[14]}$. 潘家口水库滞温层的厚度随热分层的持续而减小, 水温则缓慢增加, 从热分层初期的 $4^{\circ} \mathrm{C}$ 增至末期的 $7.7^{\circ} \mathrm{C}, 210$ 天的热分层期间仅升温 $3.7^{\circ} \mathrm{C}$.

\section{2 溶解氧层化结构特征及演化成因分析}

DO 的层化结构在热分层形成后逐渐产生, 5 月中旬水库 DO 开始出现由混合层、氧跃层、氧亏层构成的 垂向 3 层结构,并持续至 12 月下旬, DO 分层比热分层滞后约 1 个月,各层的时空变化特征与热分层相似,热 分层控制 DO 层化结构的空间分布 (图 9). DO 混合层厚度与水温表水层的厚度基本一致,2017 年至热分层 末期厚度增至 $19.8 \mathrm{~m}$, 至 12 月下旬层化结构消亡前厚度增至 $28.4 \mathrm{~m}$. 氧跃层厚度略小于温跃层厚度, 位于 温跃层内上侧, 其厚度随时间的变化与温跃层类似, 也呈先增后减的趋势, 8 月份厚度最大达到 $9.75 \mathrm{~m}$. 氧亏 层厚度在 DO 层化初期超过 $55 \mathrm{~m}$, 随后逐渐减小, 在层化结构消亡前厚度约为 $30 \mathrm{~m}$.

水库热分层使得垂向各层水体的水动力差异显著, 为 $\mathrm{DO}$ 的垂向分层提供了分异性物理环境, 同时在各 水层内不同的生化过程作用下,垂向各层 DO 呈现不同的演变特征. DO 混合层位于热分层的表水层内,水 体垂向混合均匀, DO 浓度的垂向分布也较为均匀. 混合层接受大气复氧的同时, 藻类等浮游植物有足够的 阳光进行光合作用产生氧 ${ }^{[29]}$. 潘家口水库 $\mathrm{N} 、 \mathrm{P}$ 等生源要素充足, 热分层期水温适宜, 藻类大量繁殖, 如 2017 年 8 月表层水体叶绿素 $a$ 浓度达到 $15.57 \mu \mathrm{g} / \mathrm{L}$ (图 10), 是热分层期间混合层水体 DO 浓度过饱和的主要 原因.

氧跃层位于温跃层内上侧, 其 DO 浓度随水深增加而急剧降低、甚至出现垂向最小值, 其主要原因可能 有: (1) 温跃层较大的温度梯度限制了垂向掺混,且热分层强稳定期温跃层垂向扩散系数小,上层水体对温 
跃层 DO 补给较少 ${ }^{[5,30]} ;$; (2) 温跃层内浮游动物呼吸作用 耗氧, 同时浮游动物捕食大量浮游植物, 导致光合作用产 氧量减少 ${ }^{[31]} ;$; (3) 表水层藻类繁殖后大量藻类死亡形成 的有机颗粒物在沉降过程中分解耗氧 ${ }^{[28,32]}$. Kalff 等指 出, 进人温跃层的大部分有机颗粒体积较小 (除硅藻外), 密度与淡水密度接近, 由沉降公式可知其沉降速度很小, $10 \mu \mathrm{m}$ 的颗粒沉降 $10 \mathrm{~m}$ 需要 40 天 $^{[2]}$. 潘家口水库热分层 期间温跃层的厚度一般在 $10 \mathrm{~m}$ 以上,体积较小的有机颗 粒有充足的时间矿化分解, 并在此过程中大量耗氧. 经此 矿化过程后, 沉降至氧亏层的有机颗粒大大减少, 且多为 体积较大、沉降速度较大的颗粒. 以 2017 年 8 月监测数 据为例 (图 10), 8 月水库处于稳定热分层状态, 水体透明 度 $1.3 \mathrm{~m}$, 上层混合层厚度为 $3.8 \mathrm{~m}$, 氧跃层水深范围为 $3.8 \sim 9.4 \mathrm{~m}$; 在水深 $4.5 \mathrm{~m}$ 处 (位于氧跃层), $\mathrm{DO}$ 浓度为 $9.72 \mathrm{mg} / \mathrm{L}$, 叶绿素 $a$ 浓度为 $10.19 \mu \mathrm{g} / \mathrm{L}$; 在水深 $7.1 \mathrm{~m}$ 处 (同样位于氧跃层), DO 和叶绿素 $a$ 浓度分别下降至 1.2 $\mathrm{mg} / \mathrm{L}$ 和 $2.53 \mu \mathrm{g} / \mathrm{L}$, 显然 DO 和叶绿素 $a$ 浓度均随水深同

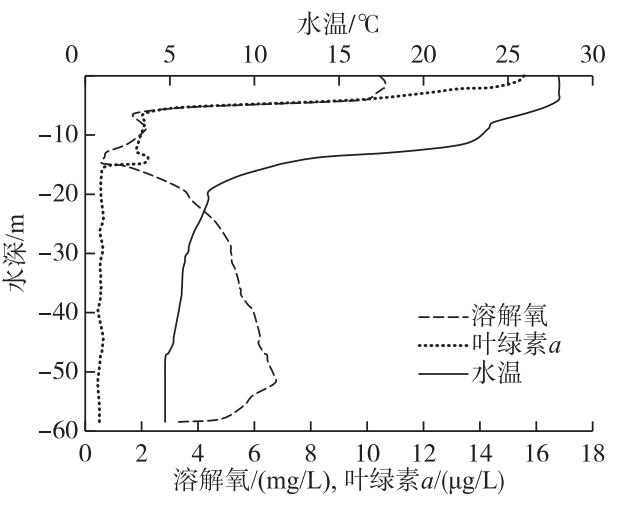

图 10 潘家口水库 2017 年 8 月垂向水温、 溶解氧和叶绿素 $a$ 浓度的剖面变化

Fig.10 Depth profiles of water temperature, dissolved oxygen and chlorophyll- $a$ concentrations of the Panjiakou Reservoir in August of 2017 步、急剧降低,氧跃层下部处于厌氧状态.

氧亏层位于水库的下层滞温层, 水体扰动小, 在沉积物耗氧作用下 DO 浓度持续、缓慢下降. Müller 等指 出, 氧亏层的耗氧主要是沉积物一水界面耗氧, 包括水体向沉积物扩散的氧消耗和沉积物向水体扩散的还原 物质氧化耗氧两部分, 沉降至氧跃层的有机颗粒多体积较大、沉降速度较快, 能快速沉降至沉积物表面, 有 机颗粒在氧亏层沉降过程中耗氧有限, 基本可以忽略不计 ${ }^{[11]}$. Matzinger 等在对滞温层 DO 的研究中提出, 沉 积物一水界面的耗氧物质主要源自近期沉降至沉积物表面的有机物以及 10 年内形成的沉积物中还原物质 的释放, 其大小由水体当前的生产力控制 ${ }^{[13,33]}$. 对潘家口水库的监测表明 (图 10), 水库氧亏层中叶绿素 $a$ 浓度较低且在垂向上变化不大, 表明从水库上层输人到氧亏层的有机物通量与氧亏层沉降至底部的有机物 通量基本一致, 沉降过程中消耗有限. 长期以来潘家口水库上游来水 TP、TN 浓度较高, 例如 2017 年全年上 游来水 TP、TN 平均浓度分别为 0.25 和 $6.74 \mathrm{mg} / \mathrm{L}$, 水库的生源要素充足、生产力较高, 加之长期的网箱养 殖, 导致水库底部沉积物处于重度污染状态, 有机污染相对严重 ${ }^{[22]}$, 水库底部耗氧物质十分丰富, 热分层期 间水库底部 DO 浓度逐渐降低.

水体缺氧会威胁水库的水生态健康, 研究表明底层鱼类对 DO 浓度的承受能力下限为 $3 \sim 4 \mathrm{mg} / \mathrm{L}$, 当 DO 浓度小于 $2 \mathrm{mg} / \mathrm{L}$ 时底栖动物会出现行为异常, DO 浓度小于 $0.5 \mathrm{mg} / \mathrm{L}$ 时底栖动物会放弃洞穴、暴露在沉积 物一水界面, 出现大量死亡 ${ }^{[34-35]}$. 采用 $\mathrm{EPA}$ 确定的 $2 \mathrm{mg} / \mathrm{L}$ 的缺氧标准 ${ }^{[36]}$, 可以判定潘家口水库在 2017 年 10 月库底开始出现缺氧, 缺氧持续至 12 月热分层结束、垂向水体混合均匀时为止; 2018 年 11 月底库底 DO 浓度略低于 $2 \mathrm{mg} / \mathrm{L}$, 水库仅短暂的缺氧. 计算表明, 潘家口水库热分层期间滞温层底部耗氧率约为 0.045 $\mathrm{mg} /(\mathrm{L} \cdot \mathrm{d})$, 与其他富营养化热分层湖库相比耗氧率偏低, 特别是与同流域、污染状况类似的大黑汀水库 (耗 氧率 $0.33 \mathrm{mg} /(\mathrm{L} \cdot \mathrm{d}))$ 相比 ${ }^{[27]}$, 潘家口水库底部耗氧率仅为大黑汀水库的 $15 \%$.

热分层期间水库底部耗氧率随水深的减少而增加, 在水深较浅的区域, 滞温层水温略有升高、耗氧率增 加、滞温层 DO 迅速消耗, 易发生缺氧. Harris 等基于代谢理论的研究表明, 水体初级生产力和呼吸作用随水 温的升高而增加, 大西洋东北部河口水温增加 $4^{\circ} \mathrm{C}$, 水体初级生产力增加 $20 \%$, 呼吸作用增加 $43 \%$, 底部水体 缺氧的可能性也相应增加 ${ }^{[37]}$. Hansen 等指出, 丹麦海峡水温升高 $4^{\circ} \mathrm{C}$, 底部 DO 浓度降低 $0.96 \mathrm{mg} / \mathrm{L}^{[38]}$. Müller 等基于对欧洲多个湖库的研究指出, 热分层水体底部耗氧率随滞温层厚度减小线性增加, 当滞温层厚 度较小时, 滞温层底部耗氧率高, 底部 DO 浓度将迅速下降, 导致在较短的时间内出现缺氧区 ${ }^{[11]}$. 2017 年和 2018 年潘家口水库一直保持高水位运行, 平均水深为 $65.44 \mathrm{~m}$, 在水库库中一坝前水深较大的区域, 热分层 期间底部耗氧率较小, 底部均保持有相对较高的 DO 浓度. 在库尾水深小于 $25 \mathrm{~m}$ 的区域,热分层期间滞温层 
底部水温相对较高, 以 2017 年 8 月为例, 库尾最大水深 20 和 $25 \mathrm{~m}$ 处底部水温分别为 8.6 和 $7.2^{\circ} \mathrm{C}$, 比水深最 大的坝前库底水温分别高 4.2 和 $2.8^{\circ} \mathrm{C}$, 相对较高的底部水温使得底部耗氧率相对较大, 滞温层更易缺氧. 据 此可认为,为保证潘家口水库供水水质、抑制坝前区域出现缺氧区,应尽量保持该水库在较高水位下运行.

\section{3 潘家口水库的水质响应分析}

水库的营养型从贫营养、中营养、富营养到超富营养逐渐演变 ${ }^{[39]}$. 在外来污染负荷的持续作用下, 热分 层水库水环境演变过程中其滞温层一般经历如下过程 (图 11): 水体贫营养, 水生物生产水平低, 底部 DO 充 足; 随着外源污染增加, 水体逐渐变成中营养, 藻类等大量繁殖, 大量有机物下沉, 底部耗氧量增加、DO 浓度 逐渐降低; 外源污染进一步增加, 水体进人富营养状态, 底部出现局部、短时间的缺氧, 沉积物中磷的释放量 增加, 底栖生物群落发生大规模变化, 物种丰富度大量降低、生长速率减慢 ${ }^{[35]}$; 随着氧化物的消耗, 水体缺乏 缓冲缺氧的能力, 底部缺氧范围扩大、持续时间增加, 甚至出现无氧, 还原性物质大量产生, 阻止水体再氧 化, 水体进人超富营养状态, 水库一旦处于这个阶段缺氧事件将更频繁、更大范围的发生 ${ }^{[40]}$. 热分层水体水 环境演化过程中, 底部 DO 浓度是最直接的指示指标 ${ }^{[41]}$.

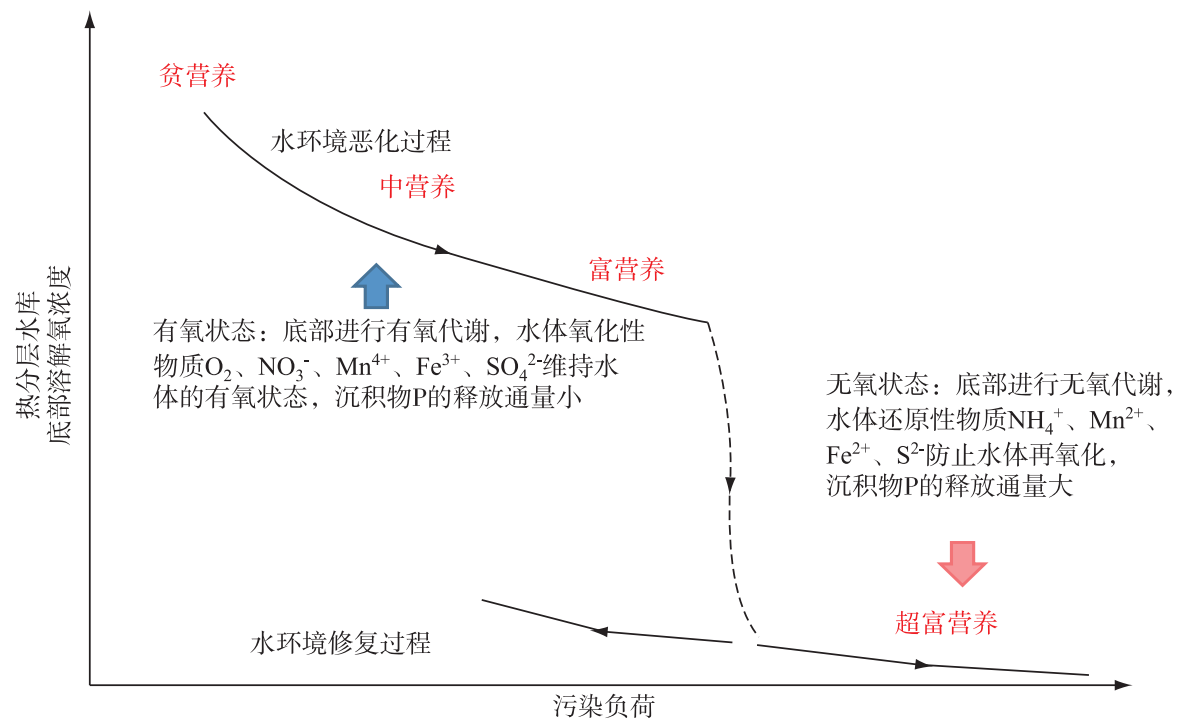

图 11 热分层水库以底部溶解氧浓度为指示的水环境演变

Fig.11 Water environment evolution diagram of thermal stratification reservoir indicated by bottom dissolved oxygen concentration

当前, 潘家口水库在热分层末期底部已出现缺氧区, 为了进一步查清该水库的水环境状况, 对该水库 2018 年 5 月、8 月、11 月开展了 3 次垂向水质监测. 结果表明, 5 月、8 月两次监测中各项指标在滞温层未见 明显的浓度变化, TP 浓度约为 $0.15 \mathrm{mg} / \mathrm{L}, \mathrm{Fe} 、 \mathrm{Mn}$ 等指标浓度均低于检出限; 水库热分层末期 11 月的监测发 现, 各项指标在滞温层内距离库底 $5 \mathrm{~m}$ 以上的范围内基本没有浓度差, 而在距离库底 $5 \mathrm{~m}$ 范围内随着水深的 增加 TP、Mn 等物质浓度升高. 11 月 $\mathrm{TP}$ 浓度在距离库底 $1 、 3 、 5 \mathrm{~m}$ 处分别为 $0.48 、 0.29$ 和 $0.18 \mathrm{mg} / \mathrm{L} ; \mathrm{Mn}$ 在距 离库底 1 和 $3 \mathrm{~m}$ 处的浓度分别为 0.68 和 $0.35 \mathrm{mg} / \mathrm{L}, 5 \mathrm{~m}$ 处低于检出限; Fe 的浓度低于检出限(图 12).

磷 $(\mathrm{P})$ 在沉积物中主要以 Fe-P、Mn-P 等形式存在,潘家口水库所在滦河流域铁矿资源丰富,水库沉积物 中 Fe-P 含量远远大于 Mn-P ${ }^{[23]}$. Fe-P 和 Mn-P 均对氧化还原作用敏感, 在水体处于氧化环境 $(\mathrm{DO}>4 \mathrm{mg} / \mathrm{L})$ 下稳定存在; 但随着底部 DO 浓度降低, 氧化性相对较强的 $\mathrm{Mn}^{4+}$ 首先被还原, 沉积物释放 $\mathrm{Mn}^{2+}$ 和 $\mathrm{P}$; 在 $\mathrm{DO}$ 浓 度降低至 $1 \mathrm{mg} / \mathrm{L}$ 以下时, $\mathrm{Fe}^{3+}$ 被还原, 在底部水体中可监测到 $\mathrm{Fe}^{2+}$ 和 $\mathrm{P}^{[42]}$.

目前仅在热分层末期潘家口水库库底监测到 $\mathrm{Mn}$, 未发现 $\mathrm{Fe}$ 浓度升高, 说明水库在热分层末期库底 DO 浓度最低时沉积物中 Mn-P 发生了还原、释放, 尚未出现 Fe-P 还原、释放. 若库底 DO 浓度进一步降低, 潘家 


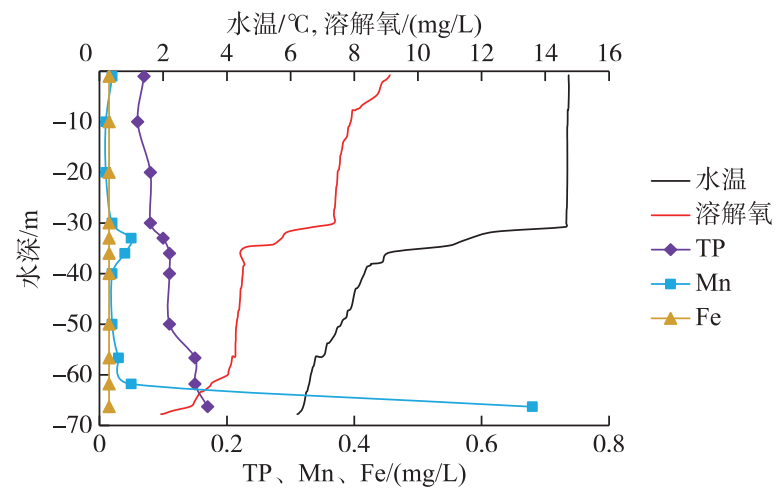

图 12 潘家口水库 2018 年 11 月垂向水质剖面图 (监测点 16)

Fig.12 Water quality profiles for the Panjiakou Reservoir in November of 2018 (monitoring point 16)

口水库很可能发生 Fe-P 的还原, 而与之伴随的更大量的磷等内源污染释放, 将导致水质进一步的恶化, 这种 现象已经在位于潘家口水库下游、污染状况类似的大黑汀水库发生 ${ }^{[28]}$. 可以认为, 当前潘家口水库正处于 库底局部、短时间缺氧的阶段,正在逼近库底发生长期、大范围缺氧,甚至无氧现象的临界点.

\section{4 结论}

2017 年和 2018 年对潘家口水库水温和 DO 浓度垂向分布的监测表明,水库存在显著的季节性热分层现 象, 全年库表、库底水温在 $2.4 \sim 30.2^{\circ} \mathrm{C} 、 2.4 \sim 7.7^{\circ} \mathrm{C}$ 范围内波动; 4 月中旬 -11 月底的热分层期间水温垂向分 布呈单温跃结构, 垂向分为表水层、温跃层和滞温层, 温跃层温差较大, 有效抑制了垂向上热量的传递, 使得 滞温层升温缓慢.

潘家口水库的水温分层控制 DO 分层,热分层开始后 DO 的垂向分层逐渐形成,垂向上呈现混合层、氧 跃层和氧亏层的 3 层结构, 各层垂向各层变化特征与水温分层相似. 混合层受浮游藻类影响, DO 处于过饱 和状态; 氧跃层受生物呼吸作用及有机物分解作用影响, DO 浓度随水深增加急剧下降, 7-8 月处于缺氧状 态; 氧亏层受重污染沉积物耗氧的影响, 底部 DO 浓度随热分层的持续而下降, 热分层末期库底可能出现缺 氧现象. 水库热分层为 DO 层化结构的形成提供了垂向分异性物理环境, 各层不同生化过程的作用为 DO 浓 度空间差异性演变提供了驱动力.

潘家口水库热分层末期 DO 浓度降低的同时, 已监测到沉积物中 Mn 还原、Mn-P 解吸释放等现象, 但目 前尚未发生 Fe 还原以及沉积物中含量较高的 Fe-P 解吸释放. 可以认为, 潘家口水库目前正在逼近热分期期 间库底出现历时较长、大范围无氧环境, 导致内源污染大量释放的临界点, 建议水库应尽量保持在较高水位 下运行.

\section{5 参考文献}

[ 1 ] Sheng CM, Lian JJ, Liu F et al. Force analysis on water barrier curtain for released flow with low temperature from deep reservoirs. Journal of Hydraulic Engineering, 2016, 47(12): 1548-1557. [盛传明, 练继建, 刘昉等. 深水水库下泄低 温水治理挡水幕布受力研究. 水利学报, 2016, 47(12): 1548-1557.]

[ 2 ] Kalff J ed. Limnology: inland water ecosystems. Beijing: Higher Education Press, 2011. [Kalff J. 湖沼学一一内陆水生 态系统. 北京: 高等教育出版社, 2011.]

[ 3 ] Zhang Y, Wu Z, Liu M et al. Dissolved oxygen stratification and response to thermal structure and long-term climate change in a large and deep subtropical reservoir (Lake Qiandaohu, China). Water Research, 2015, 75: 249-258. DOI: 10.1016/j.watres. 2015.02.052.

[ 4 ] Wang Y, Xia H, Fu J et al. Water quality change in reservoirs of Shenzhen, China: detection using LANDSAT/TM data. Science of the Total Environment, 2004, 328(1/2/3) : 195-206. DOI: 10.1016/j.scitotenv.2004.02.020. 
[ 5 ] Neol M, Burns CR. PROJECT HYPO: an intensive study of the Lake Erie central basin hypolimnion and related surface water phenomena. CCIW, Paper No.6 and US Envir. Prot. Agency. Tech. Rep., TS-05-71-208-24, 1972.

[ 6 ] Volkmar EC, Dahlgren RA. Biological oxygen demand dynamics in the lower San Joaquin River, California. Environmental Science \& Technology, 2006, 40(18) : 5653-5660. DOI: 10.1021/es0525399.

[ 7 ] Jin XC, Liu HL, Tu QY et al eds. Eutrophication of lakes in China. Beijing: China Environmental Science Press, 1990. [金相灿，刘鸿亮，屠清瑛等. 中国湖泊富营养化. 北京: 中国环境科学出版社，1990. ]

[ 8 ] Huang YL, Ji DB, Hui EQ et al eds. Stream ecology: Structure and function of running waters. Beijing: China Water \& Power Press, 2017. [黄钰铃, 纪道斌, 惠二青等. 河流生态学. 北京: 中国水利水电出版社, 2017.]

[ 9 ] Foley B, Jones ID, Maberly SC et al. Long-term changes in oxygen depletion in a small temperate lake: effects of climate change and eutrophication. Freshwater Biology, 2012, 57(2) : 278-289. DOI: 10.1111/j.1365-2427.2011.02662.x.

[10] Friedrich J, Janssen F, Aleynik D et al. Investigating hypoxia in aquatic environments: diverse approaches to addressing a complex phenomenon. Biogeosciences, 2014, 11(4) : 1215-1259. DOI: 10.5194/bg-11-1215-2014.

[11] Müller B, Bryant LD, Matzinger A et al. Hypolimnetic oxygen depletion in eutrophic lakes. Environmental Science \& Technology, 2012, 46(18) : 9964-9971. DOI: 10.1021/es301422r.

[12] Wetzel RG ed. Limnology: Lake and river ecosystems (3rd ed). San Diego, CA: Academic Press, 2001.

[13] Du YL, Peng WQ, Liu C. A review of dissolved oxygen variation and distribution in the stratified lakes or reservoirs. Journal of Hydraulic Engineering, 2019, 50(8) : 990-998. [杜彦良, 彭文启, 刘畅. 分层湖库溶解氧时空特性研究进展. 水利学报, 2019, 50(8): 990-998.]

[14] Li XP ed. Limnology. Beijing: Science Press, 2013. [李小平. 湖泊学. 北京: 科学出版社, 2013.]

[15] LaBounty JF, Burns NM. Long-term increases in oxygen depletion in the bottom waters of Boulder Basin, Lake Mead, Nevada-Arizona, USA. Lake and Reservoir Management, 2007, 23(1) : 69-82. DOI: 10.1080/07438140709353911.

[16] Cornett RJ, Rigler FH. Hypolinimetic oxygen deficits: their prediction and interpretation. Science ( New York, N.Y.), 1979, 205(4406) : 580-581. DOI: 10.1126/science.205.4406.580

[17] Wang SM, Han SL, Fan LC et al. Study on eutrophication control in inter-basin water supplying sources of canyon type. Haihe Water Resources, 2009, (3) : 19-23. [王少明, 韩守亮, 范兰池等. 跨流域峡谷型供水水源地富营养化防治研 究. 海河水利, 2009, (3): 19-23.]

[18] Chen C, Zhang M, Qu XD et al. The spatial-temporal pattern dynamics of the water environment in Panjiakou-Daheiting Reservoir. Chinese Journal of Applied and Environmental Biology, 2016, 22(6) : 1082-1088. DOI: 10.3724/SP.J.1145. 2016.01012. [ 陈勇, 张敏, 渠晓东等. 潘大水库水环境时空格局演变动态. 应用与环境生物学报, 2016, 22 (6): 1082-1088.

[19] Xu WZ. The study of climate change impact on algal growth in Panjiakou Reservoir [ Dissertation]. Chongqing: Chongqing Jiaotong University, 2016. [徐婉珍. 潘家口水库藻类生长对气候变化响应的研究 [学位论文]. 重庆: 重庆交通大 学, 2016.]

[20 Editorial Board for Records of YiLuan Water Control Project ed. Records of YiLuan Water control Project. Tianjin: Tianjin Science and Technology Press, 2013. [引滦枢纽工程志编委会. 引滦枢纽工程志. 天津: 天津科学技术出版 社, 2013.]

[21] Wang Y, Xing HY, Zhao EL et al. Analysis of water pollution status and control measures of Panjiakou-Daheiting. Haihe Water Resources, 2016, (3) : 17-19. [王燕, 邢海燕, 赵恩灵等. 潘家口、大黑汀水库水污染现状及治理措施浅析. 海河水利, 2016, (3) : 17-19.]

[22] Zhu X, Zhang M, Qu XD et al. Contamination status and speciation for the sediment nutrients in Panjiakou-Daheiting. Chinese Journal of Applied Ecology, 2018, 29(11) : 3847-3856. DOI: 10.13287/J.1001-9332.201811.036. [ 朱翔, 张 敏, 渠晓东等. 潘大水库表层沉积物营养盐污染状况及赋存形态. 应用生态学报, 2018, 29(11) : 3847-3856.]

[23] Kobler U, Wüest A, Schmid M. Effects of lake-reservoir pumped-storage operations on temperature and water quality. Sustainability, 2018, 10(6) : 1968. DOI: 10.3390/su10061968.

[24] Wilhelm S, Adrian R. Impact of summer warming on the thermal characteristics of a polymictic lake and consequences for oxygen, nutrients and phytoplankton. Freshwater Biology, 2007: 189119471. DOI: 10.1111/j.1365-2427.2007.01887.x.

[25] Robert J, Colley D. Mixing depths in New Zealand lakes. New Zealand Journal of Marine and Freshwater Research, 1988, 22 (4) : 517-528. DOI: 10.1080/00288330.1988.9516322. 
[26] Zhang SJ. Study on water temperature structure spatial and temporal variability in reservoirs [Dissertation]. Beijing: Beijing Normal University, 2010. [张士杰. 我国大型水库水温结构时空变异特性研究 [学位论文]. 北京: 北京师范大 学, 2010.]

[27] Liu C. Evolution, driving factors and inhibition conditions of hypoxia process in thermal stratified reservoirs: a case study of Daheiting reservoir [Dissertation]. Beijing: China Institute of Water Resources and Hydropower Research, 2019. [刘畅. 热分层水库缺氧区演化机理、驱动因素及抑制条件研究——以大黑汀水库为例 [学位论文]. 北京: 中国水利水电 科学研究院, 2019.]

[28] Ji ZG ed. Hydrodynamics and water quality: modeling rivers, lakes and estuaries. Beijing: China Ocean Press, 2012. [季 振刚. 水动力学和水质——河流、湖泊及河口数值模拟. 北京: 海洋出版社, 2012.]

[29] Zhang M, Qu XD, Chen Y et al. The aquatic organism communities of the Panjiakou-Daheiting Reservoir and the bioassessment of water quality. Chinese Journal of Ecology, 2016, 35(10) : 2774-2782. DOI: 10.13292/j.1000-4890.201610.001. [张敏, 渠晓东, 陈勇等. 京津冀重要水源地潘大水库水生生物群落结构及水质生物学评价. 生态学杂志, 2016, 35(10): 2774-2782.]

[30] Li H. Research on convection-dominated stratification and mixing of the little mountain reservoir: a case of a reservoir on Fushan mountain [Dissertation]. Qingdao: Qingdao University, 2018. [李红. 热对流主导的山区小水库分层与混合研 究——以浮山前水库为例 [学位论文]. 青岛: 青岛大学, 2018.]

[31] Boehrer B, Schultze M. Stratification of lakes. Reviews of Geophysices, 2008, 46(2) : 1-27. DOI: 10.1029/2006rg000210.

[32] Nix J. Contribution of hypolimnetic water on metalimnetic dissolved oxygen minima in a reservoir. Water Resources Research, 1981, 17(2) : 329-332. DOI: 10.1029/WR017i002p00329.

[33] Matzinger A, Müller B, Niederhauser P et al. Hypolimnetic oxygen consumption by sediment-based reduced substances in former eutrophic lakes. Limnology and Oceanography, 2010, 55(5) : 2073-2084. DOI: 10.4319/lo.2010.55.5.2073.

[34] Robert JD, Rutger R. Spreading dead zones and consequences for marine ecosystems. Science, 2008, 321 (5891) : 926 929. DOI: $10.1126 /$ science.1156401.

[35] Diaz R, Rosenberg R. Marine benthic hypoxia: A review of its ecological effects and the behavioural response of benthic macrofauna. Oceanography and Morine Biology: An Annual Review, 1995, 33: 245-303. DOI: 10. 1371/journal. pone.0049795.

[36] US EPA ed. Nutrient criteria technical guidance manual: Lakes and reservoirs. Washington, DC, 2000.

[37] Harris LA, Duarte CM, Nixon SW. Allometric laws and prediction in estuarine and coastal ecology. Estuaries and Coasts, 2006, 29(2) : 340-344. DOI: 10.1007/BF02782002.

[38] Hansen JLS, Bendtsen J eds. Climatic induced effects on marine ecosystems. Roskilde: National Environmental Research Institute, 2006: 598.

[39] Nürnberg GK. Trophic state of clear and colored, soft- and hardwater lakes with special consideration of nutrients, anoxia, phytoplankton and fish. Lake and Reservoir Management, 1996, 12(4) : 432-447. DOI: 10.1080/07438149609354283.

[40] Holmer M, Duarte CM, Marbá N. Sulfur cycling and seagrass (Posidonia oceanica) status in carbonate sediments. Biogeochemistry, 2003, 66(3) : 223-239. DOI: 10.2307/1469894.

[41] Daniel J, Conley JCRV. Ecosystem thresholds with hypoxia. Hydrobiologia, 2009, 629: 21-29. DOI: 10.1007/s10750009-9764-2.

[42] White DJ, Noll MR, Makarewicz JC. Does manganese influence phosphorus cycling under suboxic lake water conditions. Great Lakes Research, 2008, 34(4) : 571-580. DOI : 10.3394/0380-1330-34.4.571. 